\title{
Detection and treatment of complete vascular ring in an elderly woman with dysphagia
}

Akihito Muto, MD, PhD, Toshiya Nishibe, MD, PhD, Yuka Kondo, MD, PhD, Masato Sato, MD, PhD, and Motomi Ando, MD, PhD, Aichi, Japan

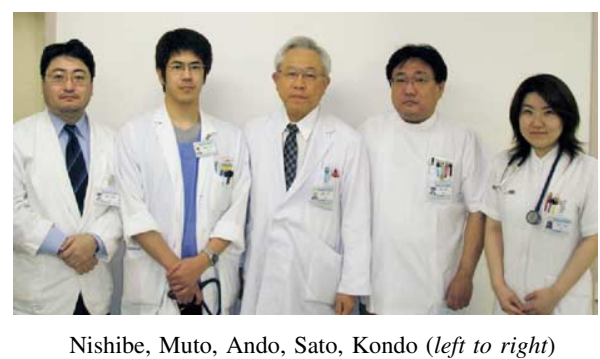

V ascular ring in adult patients is a rare anomaly in which the aortic arch and its branches compress the trachea, esophagus, or both. We describe the case of a 73-year-old woman with dysphagia caused by compression by complete vascular ring. This is the oldest patient reported in the English-language literature in whom complete vascular ring detected and treated surgically.

\section{Clinical Summary}

A 73-year-old woman was noted to have dysphagia when she was hospitalized for mild cerebral infarction. During the hospitalization, she lost $5 \mathrm{~kg}$ body weight and reported dysphagia with intermittent substernal discomfort. There were no respiratory symptoms. Stenosis of the esophagus was suspected, and she was admitted to our department.

An esophagogram revealed compression by a retroesophageal mass. Computed tomography $(\mathrm{CT})$ with contrast agent revealed a double aortic arch that 3-dimensional (3D) CT indicated was a clear right aortic arch dominant-type complete vascular ring (Mayo Clinic classification type IA), in which the left common carotid and left subclavian arteries arose from the smaller left arch with mild calcification. The double arches were joined as the left descending aorta with Kommerell diverticulum (Figure 1). ${ }^{1}$ Other examinations produced no particular findings, such as congenital heart anomalies or esophageal tumor.

The surgical approach used was through the fourth interspace rib with a fifth costotomy from a left posterolateral thoracotomy. The ligamentum arteriosum was divided after both aortic arches and the left subclavian artery, ligamentum arteriosum, and nerves had been dissected out completely (Figure 2). The left aortic arch was divided between clamps close to its junction with the descending aorta, and its ends were closed with a continuous suture (4-0 polypropylene) with covering felt sheets. The Kommerell diverticulum was wrapped with the felt sheet, and this felt was sutured

From the Department of Surgery, Division of Cardiovascular Surgery, Fujita Health University Hospital, Toyoake, Aichi, Japan.

Received for publication March 11, 2005; accepted for publication March 23, 2005.

Address for reprints: Akihito Muto, MD, PhD, Department of Surgery, Division of Cardiovascular Surgery, Fujita Health University, 1-98 Dengakugakubo, Kutukake, Toyoake, Aichi 470-1192, Japan (E-mail: akiyann@hkg.odn.ne.jp)

J Thorac Cardiovasc Surg 2005;130:585-6

$0022-5223 / \$ 30.00$

Copyright $\odot 2005$ by The American Association for Thoracic Surgery doi:10.1016/j.jtcvs.2005.03.027 to the periosteum of an adjacent rib to retract the descending aorta laterally and posteriorly away from the esophagus. The operation was completed by closing the chest wound after insertion of a single intercostal drainage tube. After surgery, the patient recovered with no remarkable complications; she could consume solid foods and was gaining weight when she was discharged.

\section{Discussion}

Vascular rings are rare causes of dysphagia and dyspnea in adult patients. They represent a congenital anomaly that accounts for $1 \%$ to $2 \%$ of cases of congenital heart disease, in which the aortic arch and its branches completely or incompletely encircle and compress the trachea, esophagus, or both., ${ }^{2,3}$ This condition is mainly detected in infants or children with tracheoesophageal compressive syndromes, and curative management in this population has been described in many series. However, the management, surgical technique, and prognosis in adult patients with vascular rings causing symptoms have not been clarified. Symptomatic vascular

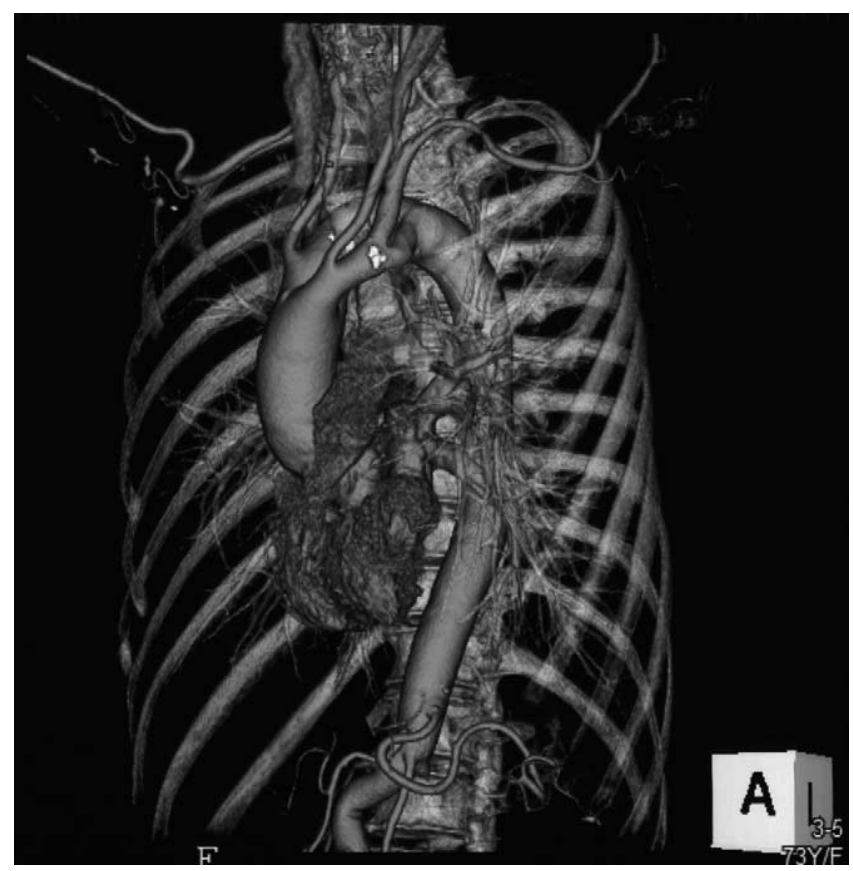

Figure 1. 3D CT with contrast agent revealed double aortic arch, which was clarified as right aortic arch dominant-type complete vascular ring. Left common carotid and left subclavian arteries arose from smaller left arch, with mild calcification and Kommerell diverticulum. 


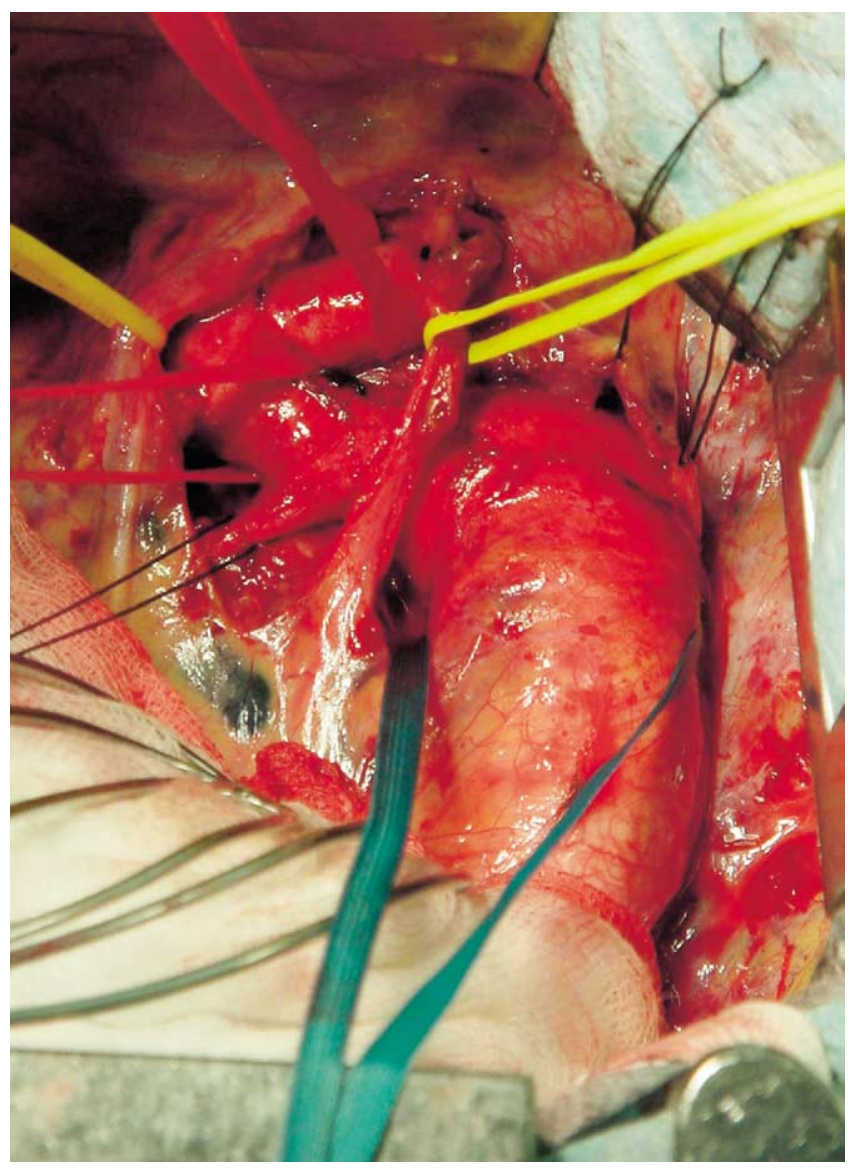

Figure 2. Intraoperative view, looking toward cranium, showing left subclavian artery (upper red tape), phrenic nerve (left yellow tape), vagus nerve (right yellow tape), left aortic arch (left red tape), ligamentum arteriosum (black string), and descending aorta (green tape).

ring in adult patients has been detected at a mean age ( \pm SD) of $36.4 \pm 12$ years. ${ }^{4}$ Our patient represents the oldest detected case of complete vascular ring that was treated surgically to be reported on PubMed, and we encountered various age-related problems in the treatment of this patient.
Grathwohl and colleagues ${ }^{4}$ reported 1 case and reviewed numerous studies of vascular rings in adults. They concluded that magnetic resonance imaging is excellent for both confirming and defining aortic anomalies. However, van Son and Starr ${ }^{5}$ suggested that ultrafast $\mathrm{CT}$ with $3 \mathrm{D}$ reconstruction provides even greater anatomic detail. In our case, the anatomic detail was determined more rapidly, with fewer limitations, and at a higher spatial resolution by $3 \mathrm{D} \mathrm{CT}$ than by magnetic resonance imaging.

The surgical treatment for vascular ring in adults is reportedly not difficult, and the follow-up results and prognosis have been satisfactory. ${ }^{4}$ Despite the fact that our patient had various problems for surgery-age-related changes in the vertebrae and thorax, atherosclerotic changes with calcification, and Kommerell diverticulum in the smaller left arch-her symptoms improved rapidly. In infants and children, surgical techniques have been developed to divide vascular rings with video-assisted thoracoscopy. ${ }^{2}$ Because of the previously mentioned problems in our case, however, we suggest that the surgery for adult cases of vascular ring should usually involve thoracotomy.

In conclusion, we report here on the oldest patient in whom complete vascular ring was detected and treated surgically. In our case, 3D CT was effective in both detection and evaluation. The management and outcome of the patient were favorable, although the surgery needed to allow for age-related changes, such as deformity of the thorax and atherosclerosis.

\section{References}

1. van Son JA, Julsrud PR, Hagler DJ, Sim EK, Puga FJ, Schaff HV, et al. Imaging strategies for vascular rings. Ann Thorac Surg. 1994;57:60410.

2. Kouchoukos NT, Blackstone EH, Doty DB, Hanley FL, Krap RB. Vascular ring and sling: In: Kirklin JW, Barratt-Boyes BG, editors. Cardiac surgery, vol 2. 3rd ed. Elsevier Science: Philadelphia; 2003. p. 1415-37.

3. Backer CL, Ilbawi MN, Idriss FS, DeLeon SY. Vascular anomalies causing tracheoesophageal compression: review of experience in children. J Thorac Cardiovasc Surg. 1989;97:725-31.

4. Grathwohl KW, Afifi AY, Dilard TA, Olson JP, Heric BR. Vascular rings of the thoracic aorta in adults. Am Surg. 1999;65:1077-83.

5. van Son JA, Starr A. Demonstration of vascular ring anatomy with ultrafast computed tomography. Thorac Cardiovasc Surg. 1995;43: $120-1$. 